
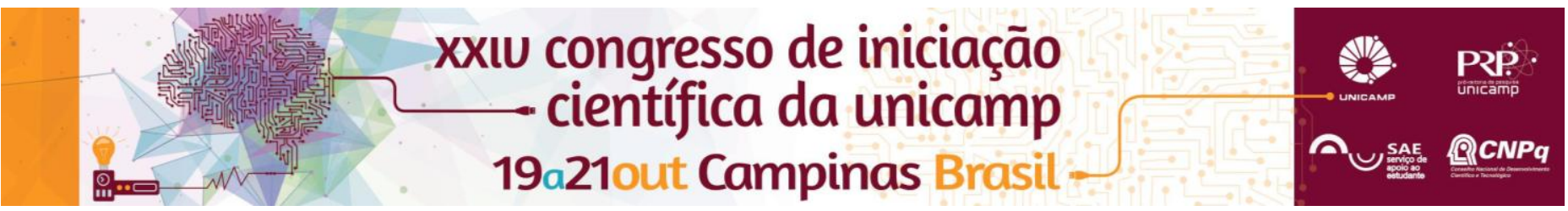

\title{
Temperatura crítica de dano fotoquímico e sua relação com o crescimento e produtividade de soja sob alta temperatura.
}

\section{Melissa R. Martino*, Eduardo C. Machado, José R. Magalhães Filho, Rafael V. Ribeiro}

\section{Resumo}

A alta temperatura do ar afeta a fotossíntese e o crescimento das plantas, podendo causar perdas na produtividade em espécies cultivadas. Entretanto, plantas de origem tropical devem ter maior tolerância a elevadas temperaturas do que as de clima temperado. A termo-tolerância fotoquímica de dez cultivares de soja provenientes de regiões tropicais e temperadas foi avaliada determinando-se a temperatura crítica de dano fotoquímico (Tc). A Tc das cultivares de soja tropicais foi, em média, $2,2^{\circ} \mathrm{C}$ maior em relação às de origem temperada, indicando sensibilidade fotoquímica distinta entre os grupos. A temperatura do ar afetou negativamente o crescimento vegetativo das plantas de clima temperado, mas não afetou a produtividade final de grãos.

\section{Palavras-chave:}

Soja, fotossíntese, temperatura.

\section{Introdução}

O aumento da temperatura média global em função das atividades antrópicas tem alterado a eficiência fotossintética das plantas e provocado perdas na produtividade agrícola. Entretanto, plantas de diferentes origens climáticas apresentam sensibilidades distintas ao calor associadas à termo-tolerância do seu aparato fotoquímico. Em outras palavras, plantas com maior temperatura crítica de dano fotoquímico (Tc) apresentam maior termo-tolerância, característica que pode ser estudada com o monitoramento da fluorescência da clorofila (SMILLIE \& NOTT, 1979). A soja, espécie amplamente cultivada no mundo, possivelmente será afetada com o aumento da temperatura prevista para as próximas décadas. O objetivo deste trabalho foi determinar a Tc de cultivares de sojas oriundas de regiões tropicais e temperadas com base na hipótese de que as cultivares de clima temperado possuem menor Tc do que as de clima tropical.

\section{Resultados e Discussão}

A Tc foi determinada a partir da curva de fluorescência mínima da clorofila em função do aumento da temperatura foliar (Ribeiro et al., 2015). Foram utilizadas cinco cultivares de soja de origem temperada (NA5909, BMX Apolo, BMX Potência, BMX Alvo e VMAX RR) e cinco tropicais (NA7337, BRS Pati, BRS Sambaíba, CD219 e M8183). Houve diferenças significativas na Tc (Tukey, $p<0,05$ ) entre as cultivares analisadas e as de origem tropicais apresentaram maior termo-tolerância fotoquímica $\left(T c>2,2^{\circ} \mathrm{C}\right)$ com $T c$ média de $42,2{ }^{\circ} \mathrm{C} v s$. $40,0^{\circ} \mathrm{C}$ nas temperadas (Figura $1 \mathrm{~A}$ e $\mathrm{B}$ ). A temperatura diurna/noturna $\left(30 \pm 2{ }^{\circ} \mathrm{C} / 22 \pm 1^{\circ} \mathrm{C}\right)$ da casa de vegetação afetou negativamente 0 crescimento vegetativo das plantas de clima temperado, mas não afetou a produtividade dessas cultivares (Figura 2A, B e C).

${ }^{1}$ Ribeiro, R. V., Santos, M. G., Pimentel, C., Machado, E. C., \& Oliveira, R. F. (2015). Can the critical temperature for photochemical damage in common bean plants be changed after a drought event? Bragantia.

${ }^{3}$ Smillie, R. M., \& Nott, R. (1979). Heat injury in leaves of alpine, temperate and

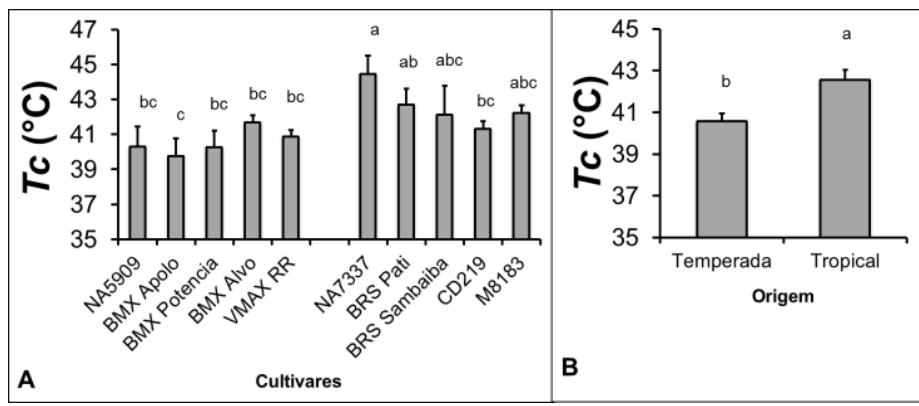

Figura 1. (A) Temperatura crítica de dano fotoquímico (Tc, em ${ }^{\circ} \mathrm{C}$ ) das dez cultivares de soja. (B) $T c$ das cultivares agrupadas em temperada e tropical. $n=3 \pm d p$.

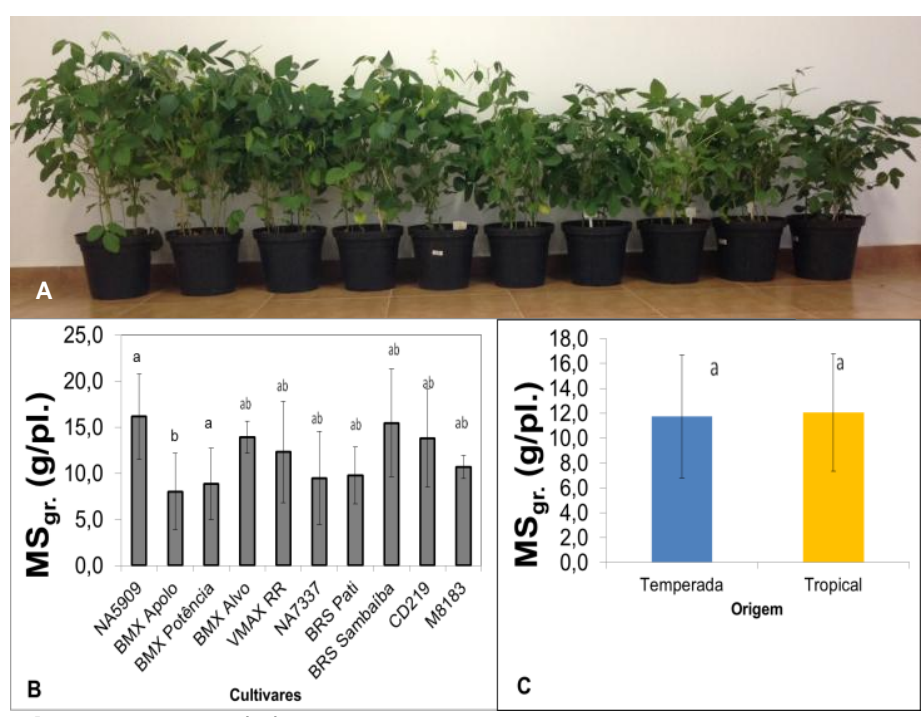

Figura 2. (A) Da esquerda para a direita, desenvolvimento vegetativo das cultivares de soja tropicais (cinco primeiras) seguidas das temperadas. (B) Massa seca de grãos por planta $\left(\mathrm{MS}_{\mathrm{gr} .}\right)$ das dez cultivares de soja. (C) $\mathrm{MS}_{\text {gr. }}$ das cultivares agrupadas em temperada e tropical . $n=7 \pm d p$.

\section{Conclusão}

As cultivares de clima tropical apresentam maior termotolerância fotoquímica do que as de clima temperado, com efeito positivo no crescimento vegetativo das plantas. tropical plants. Aust. J. Plant Physiol., 6, 135-141.

Pibic, Unicamp.

Agradecimentos 